\title{
Cognition Processes of Students with High Functioning Autism Spectrum Disorder in Solving Mathematical Problems
}

\author{
Nur Fauziyah \\ Universitas Muhammadiyah Gresik, Indonesia,nurfauziyah@umg.ac.id \\ Carol Le Lant \\ Dr., Flinders University, South Australia, Australia, carol.lelant@flinders.edu.au
}

I Ketut Budayasa

Prof., Universitas Negeri Surabaya, Indonesia, ketutbudayasa@yahoo.com

Dwi Juniati

Prof., Universitas Negeri Surabaya, Indonesia,dwi_juniati@yahoo.com

The cognition process of students with autism spectrum disorder (ASD) in solving mathematical problems is still rarely studied in depth, although the prevalence of the students is increasing. The purpose of this research was to describe the cognition processes of students with ASD in solving mathematical problems. The subjects in this research are two high school students with high functioning ASD. Data was gathered from task-based interviews. The cognition processes in solving mathematical problems involved reading and paraphrasing the problems, visualizing the problems and representing them in the form of drawings or diagrams, determining the hypothesis to create a plan to solve the problems, estimating or predicting an answer to the problem, completing computations, and finally, checking to ensure the process of problem solving resulted in a correct answer. Some characteristics of students with ASD were very perceptible during mathematical problems solving process. Differences in intelligence of the both subjects had a role in every process of cognition.

Keywords: cognition process, autism spectrum disorder, mathematical problem solving, teaching, learning

\section{INTRODUCTION}

Mathematical problems provide students an opportunity to strengthen and broaden their knowledge and to stimulate new learning. Most of the mathematical concepts can be introduced through problems based on experience already known to the students that come from the student's life or of the context of mathematics (NCTM, 2000). Solving

Citation: Fauziyah, N., Le Lant, C., Budayasa, I, K., \& Juniati, D. (2019). Cognition Processes of Students with High Functioning Autism Spectrum Disorder in Solving Mathematical Problems. International Journal of Instruction, 12(1), 457-478. https://doi.org/10.29333/iji.2019.12130a 
mathematical problems can be a challenging task for many students, because they require not only mathematical skills, but also reading comprehension, reasoning, and the ability to interpret the mathematical problem into mathematical operations (Neef, Nelles, Iwata, \& Page, 2003).

Solving mathematical problems involves cognitive processes. Cognition is the mental activity that occurs within the human brain. Mental activity commences when information is received by the senses (sensory registers) and then filtered and transmitted to the brain by sensory registers, processed and stored in the brain before subsequently recall (Solso, Maclin, \& Maclin, 2008). Cognition is how people perceive, learn, remember, and think about information in solving problems (Sternberg \& Sternberg, 2015).

The cognitive processes experienced by a student at the time of solving mathematical problems are: (1) interpreting: understand every sentence in the problem, (2) recalling: recall of factual knowledge needed to solve the problem, (3) organizing: building a coherent representation of key information in a problem called conceptual knowledge, (4) planning: designing the settlement plan, and (5) producing: implementing a plan called procedural knowledge (Anderson, 2015).

The ability of the student to solve mathematical problems is also closely related to the learning process in the class. The learning process involves not only an interaction between teacher and students but also interaction among students. The students who have social interaction disorder will affect the lack of student involvement in the learning process in the class. One characteristic of student who has social interaction or communication disorders is students with autism spectrum disorder (ASD). Students with ASD has also language disorder (Holaday, 2012). Language skills of students with ASD are more limited than children without ASD (Long, Gurka, \& Blackman, 2011). Besides communication skill and social interaction ability, there is also the cognitive ability in solving mathematical problems (Mayer, 2011). There are differences in cognitive abilities of children with and without ASD (Long et al., 2011). It has also been found that the cognitive development of student with ASD was uneven (Joseph, Tager, \& Lord, 2002).

The prevalence of autism in children is increasing. It is estimated that between 1 in 80 and 1 in 240, with an average of 1 in 110, children in the United States have ASD. ASD are claimed could occur within any age, race, ethnic and socioeconomic status, and is, on average, 4 to 5 times more common in boys than girls (Long et al., 2011; Rice, 2009). The average annual increase in ASD prevalence was $9.3 \%$ per year from 19962010, and an average of 15.5 per 1000 children in Metropolitan Atlanta (Braun et al., 2015), and 2.5 per 1000 in Canada (Elsabbagh et al., 2012). Overall ASD prevalence rates in Denmark are 6.9 per 1000 children (Parner et al., 2011), 5.1 per 1000 children in Western Australia (Bourke, Klerk, Smith, \& Leonard, 2016), 1.5 per 1000 children in Asia (Sun \& Allison, 2009), and 1.2 per 1000 children in Indonesia (Evaluation, 2017).

Therefore a study is needed to reveal in depth how the cognition processes of students with autism spectrum disorder works in mathematical problems solving. The results of 
this research can be utilized to improve the quality of the learning process, especially students with ASD.

\section{Literature Review}

\section{Mathematical Problem Solving}

Solving mathematical problems is an integral part of learning and understanding mathematics. Students need many opportunities to think, formulate and solve mathematical problems to accustom them to thinking mathematically and enabling them to apply and adapt the strategies they develop to other problems and in other contexts. Through the process of solving mathematical problems, students acquire mathematical thinking, high curiosity, and confidence in unusual situations that can help them beyond the mathematics class (NCTM, 2000).

There are five kinds of knowledge required for successful problem solving: understanding the facts, concepts, procedures, strategies, and beliefs. Facts are the factual knowledge about the characteristics of elements in the world. Concepts are conceptual knowledge, including categories, schemas, or models, whereas procedures are the procedural knowledge acquired of the step by step processes, such as how to carry out long division computations. Strategies are the strategic knowledge of general methods, such as breaking a problem into parts or thinking of a related problem. Beliefs relate to a person's attitudinal knowledge about how one's cognitive processing works (Mayer, 2011).

According to (Polya, 1948), solving mathematical problems is an attempt to find a way out of a difficulty to achieve a goal that is not so easily reached. Polya classifies mathematical problems into two types, namely: the problem to find and the problem to prove. (Polya, 1957) theory works from the basis of there being four steps in solving mathematical problems, namely the need to understand the problem, devise and carry out a plan, and then reflecting or looking back at what you have done and the outcome of your effort.

In understanding the problem, the students should be able to state the problem fluently and identify the principal components of the problem. In devising the plan, students should look at the information or concepts in the problem, and relate how the information can be used to solve the problem. When executing the plan, students draw on their conceptual and procedural knowledge. During the looking back step of problem solving, the students reflect on their answer to check whether what they have done is correct and appropriate. If students find a mistake, then the students attempt to resolve it by correcting a computational error or identifying and implementing a different strategy (Polya, 1957).

\section{Cognition Processes in Mathematical Problem Solving}

The process of cognition is a mental activity that consists of the acquisition, organization and use of information (Neisser, 2014; Reed, 2007). There is a limit on the brain's capacity to process incoming information, therefore attention is focused on important and relevant information. Further information will be stored in short-term or 
long-term memory to be recalled and used later (Marois, 2005; Matlin, 2005; Reynolds \& Flagg, 1983).

When students are faced with a problem, the brain processes the problem directly, builds a mental representation that describes the problem omit, and recalls the previously acquired information to obtain a solution to the problem. That is the processes of cognition experienced by students when solving a problem, as well as mathematical problems (Mayer, 2011).

The steps in solving mathematical problems according to Polya theory developed more detail by Montague (2013). The first step, understanding the problem, is divided into three steps; reading the problem, paraphrasing the problem by using the sentence itself without changing the meaning of the problem, and visualizing the problem to represent them in the form of drawings or diagrams. The second step is divided into two steps, determining the hypothesis to create a plan of completion of the problems and estimating to predict the answer of the problem. The third and the fourth steps have not changed, computing to do arithmetic for the solution to the problem and checking to make sure the process of problem solving is right. These steps were used as a basis by researchers to reveal the cognitive processes the students with ASD in solving mathematical problems. Problem Solving can be interpreted as a learning activity that emphasizes the scientific problem solving process. Stages in solving problems based on Polya's theory are more systematic. This is the reason for the researchers to use Polya's theory. Polya's theory is very appropriate to be applied in learning as a solution to improve students' ability to solve mathematical problems, especially mathematical word problems.

Problem solving occurs within the problem solver's cognition and can only be inferred indirectly from the problem solver's behaviour, including biological changes, introspections, and actions during problem solving (Mayer, 2011). This can reveal the cognitive process of a student when the student solves mathematical problems by observing his or her behaviour during the process of solving a problem, thinking aloud, asking questions, rephrasing, connecting prior learning and justifying answers or thinking.

\section{Mathematical Problem Solving of Students with ASD}

ASD is a developmental disorder characterized by difficulties with social interactions, communication, and engaging in unusual behaviours and/or obsessions (Frith, 2003). Individuals with ASD with average and above average intelligence are considered as having high-functioning ASD (Chiang \& Lin, 2007). More students are being identified as having ASD, and as such, a greater research focus on their progress through the education system is occurring (Fordyce, Leonhard, \& Chang, 2017).

As the number of students with ASD entering high school and accessing general education continues to grow, many educators feel unable to adapt their teaching and learning programs to meet the needs or characteristics of students with ASD, which impact on their educational success (Fleury et al., 2014). Indonesian students with ASD 
who attend school in the general and inclusive education environment access the same curriculum as their typically developing peers in common learning situations, including mathematics. However, mathematical learning and problem solving often present challenges for some students with ASD (Barnett \& Cleary, 2015).

To date, research evidence on the mathematical abilities of students with ASD has provided mixed results (Titeca, Roeyers, Josephy, \& Ceulemans, 2014). In Luculano et al. (2014), the students with ASD exhibited cognitive strengths in domains such as mathematics. On the contrary, research conducted by Bae, Chiang, \& Hickson (2015), indicated that students with ASD were significantly lower than students without ASD on mathematical word problem solving ability and everyday mathematical knowledge. Additionally, students with ASD who comprehended everyday mathematical concepts tended to be able to solve mathematical word problems (Bae et al., 2015).

The students' ability in solving mathematical problems, especially mathematical word problems, is closely related to their ability to comprehend the problems. Although students with ASD have a communication disorder, many students with ASD who are high-functioning have strengths in reading comprehension. However, most teachers lack confidence in preparation and efficiency in teaching reading to students with ASD(Spector \& Cavanaugh, 2015). To enhance reading ability in students with ASD, teachers can provide intensive intervention focusing on developing vocabulary and improving reading comprehension (Roux, Dion, Barrette, Dupéré, \& Fuchs, 2015).

Special attention from their teachers is also required by students with ASD in the classroom to increase their social interaction, spontaneous communication, and involvement in the learning process. Without it, students with ASD tend to be quiet, and speak to themselves (Tan \& Alant, 2016). Their involvement in the mathematics learning process can increase their intensity in using skills in solving mathematical problems (Whitby, 2012).

The teacher who is unfamiliar with the learning styles of students with ASD omit, may implement ineffective teaching strategies, often with the result that, students are withdraw from learning and develop negative attitudes toward learning ref. Students' specific attitude towards learning in mathematics can greatly affect the student's ability to engage with solving mathematical problems. There is a significant relationship between positive attitudes of students in learning mathematics and their ability to successfully approach mathematical problems (Demirela, Dermana, \& Karagedika, 2015).

For teachers to understand the characteristics of how students with ASD learn and solve mathematical problems, it is necessary to conduct a research project that can reveal how the cognition processes of students with ASD work when they solve mathematical problems.

This research aims to discover the cognitive processes used by students with ASD when solving mathematical problems, and asks the question "What are the cognition processes of students with ASD when attempting to solve mathematical problems?" 


\section{The Indonesian School Curriculum Model}

In Indonesia there are two kinds of education services, general and inclusive. Most, but not all, schools offering general education services use the 2013 Curriculum (abbreviated as K-13). The other general education schools use the old curriculum, the Education Unit Level Curriculum (KTSP) which has been in use since 2006 (Director General of Primary and Secondary Education, 2017). These two curricula are referred to as the regular curricula and is offered to use in schools throughout Indonesia from primary to high schools.

Schools offering an inclusive education service also use the regular curriculum. These schools provide an education to a variety of students with special educational needs, ranging from mild to moderate and severe, however, the regular curriculum is modified to meet the diverse needs of the students. The modifications of the curriculum are conducted by the curriculum development team at the school. The school curriculum development team consists of the principals, teachers, counsellors, psychologists, and other relevant experts. These adaptations are used by the class teachers to prepare individual learning programs to remove the barriers that may prevent the students from accessing and progressing through the curriculum (Minister of National Education, 2009).

The inclusive education service in Indonesia enables students with special needs to study in their local school in regular classes with their peers. The spirit of the implementation of inclusive education is to provide opportunities for all children to obtain quality education without discrimination. The implementation of inclusive education services requires the school to make adaptations in areas such as the education facilities, learning strategies and assessments. Educators at inclusive schools are educated personnel with educational qualifications in special education and psychology.

\section{METHOD}

\section{Participants of the Study}

In determining the subjects of research, the researcher conducted a search about the existence of students with ASD in locations such as resource centres, inclusive high schools, and therapy centres. From those identified with ASD, further classification took place based on whether they were high-functioning, their gender and grade level.

Based on the above search, two students with high-functioning ASD were chosen. Both were diagnosed with ASD at three years of age, are male with an IQ score above 90 and attend high school in Indonesia with exposure to the general and inclusive education systems. However, each student has experienced inclusive education at different levels during their schooling. These differences will be described in more detail below.

\section{Subject 1: Rafi}

Rafi was an eleventh-grade student, aged 16 years with an IQ score of 115 . He experienced inclusive education at primary and junior high school levels, and on moving onto high school, participated in a general education program. He has participated in 
intensive therapy from the age of three until now in a therapy center operating outside of the school. The therapy aims to teach emotional control, build confidence and increase motivation in learning, and occurs twice a week for an hour outside of the regular school hours.

Sometimes at school Rafi does not appear to be aware of his surroundings, but if greeted by staff or peers, he would respond appropriately. In the classroom, he usually sat with his typically developing peers and when engaged in the classroom learning process, would often talk to himself.

Drawing on the information provided by his teacher, Rafi has strengths in mathematics and science and experiences difficulties in learning the Indonesian language and history. Rafi identified that mathematics and science contained factual and numerical content with clear rules, whereas the Indonesian language and history lessons require him to memorize information. He often participates in and wins the Mathematics Olympiad at the national level and he often supports the learning of mathematics to his classmates.

Subject 2: Aldi

Aldi was an eleventh grader student, aged 18 years with an IQ score of 95 . He experienced general education at primary school and junior high school levels, and upon transitioning into high school, he has experienced an inclusive education. He has received intensive therapy from the age of five to nine years in a therapy centre. Like Rafi, the therapy centre was independent of the school and targeted the areas of emotional control, confidence and motivation in learning. He participated in three, one hourly session per week.

During lesson time, Aldi preferred to sit alone at the front of the class. During class discussions, he was not concerned with the class situation, even when class discussions were very actively express opinions. Most of the students in the class would actively express opinions, but Aldi did not participate, appearing preoccupied with himself. At a certain moments he would talk and laugh to himself, however, when the teacher questioned him, he would respond quickly and appropriately.

Based on the information from the teacher, Aldi has strengths in English Language lessons and experiences weakness in Mathematics and Science.

\section{Ethics/permissions}

This research obtained permission from the Minister of Education and Culture and the relevant schools. Pseudonyms have been used to protect the identity of the participants who were free to withdraw from the research without fear or prejudice at any time.

\section{Setting}

The research took place in two different high schools, one private and one public, in East Java Province in Indonesia. Rafi attended a private high school in a general education setting and Aldi attended a public high school in an inclusive education setting. Each school was located in different city. The private high school was located in 
an industrial area of city and the public high school was located in a suburb in the second largest city in Indonesia. At each school a certified educator provided support services for students with ASD.

\section{Design}

The research approach was done in a flexible and evolving style in accordance with the circumstances in the field. Adjustments were made to the factors that affect the results of the study. The results of the study cannot be generalized, but only infer actual phenomena in the field according to the research objectives. This research focused on two students with high functioning autism spectrum disorder, so this research is a case study. The approach was categorized as qualitative, while this type of research is descriptive explorative research (Merriam, 2009).

The qualitative data on the general form of words was derived from observations, interviews or documents. Qualitative data has advantages compared with quantitative data; for example qualitative data is richer in terms of descriptions and explanations (Huberman, Miles, \& Saldana, 2013).

\section{Instruments and its Validation}

In accordance with the type of the research, qualitative research, the main instrument in this research was the researcher's observations, while the auxiliary instrument was in the form of mathematical problem test instruments and instrument-guided interviews. As a main instrument, the researchers acted as a planner, collector, analyzer, interpreter and reporter of the research results. Thus the researchers have to be objective, responsive and neutral.

The material in the problems was developed based on curriculum applicable in high school level. The mathematical problem test instrument was used to collect data about the cognitive processes undertaken by the subjects in solving mathematical problems based on Polya problem solving procedures. The responses written or disclosed by the subjects in each problems solving step were used as a guide to analyze the processes of cognition conducted by the subjects.

Mathematical problem test instruments were processed by experts through content validation to validate the construction of problems, materials and language in the problems. The validators were two mathematics class teachers and two mathematics specialists from the University. The following is a mathematical problem test instrument used in this research. 
The image below shows there three triangle patterns of level 1 , level 2 , and level 3 which are made of matchsticks. It takes 3 matchsticks to make triangle level 1 , nine matchsticks to make triangle level 2 and 18 matchsticks to make triangle level 3 .

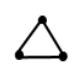

level 1

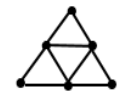

level 2

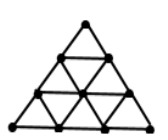

level 3

How many matchsticks are needed to make triangle level 5, 10, and $\mathrm{n}$ ?

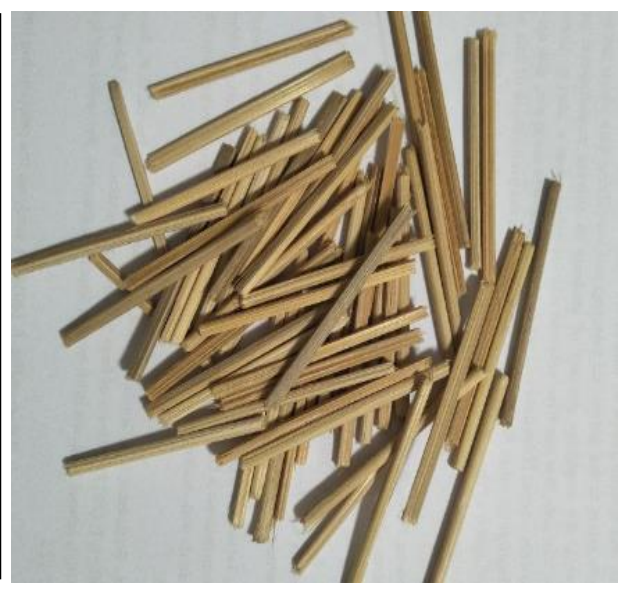

Figure 1

Mathematical problems test instrument (left) and concrete media (right)

Researchers used triangulation techniques to ensure the reliability of test instruments. The type of triangulation used by researchers is time triangulation. In this triangulation, the researchers compiled the second mathematical problem test instrument which was equivalent to the first mathematical problem test instrument. The second mathematical problem test instrument was tested on the subjects of the research several days after the subjects completed the first mathematical problem test instrument. The following is a test instrument for the second mathematical problem used for triangulation.

Some biscuits are arranged with patterns like the picture below. The first pattern requires 1 biscuit, the second pattern requires 3 biscuits and the third pattern requires 6 biscuits.
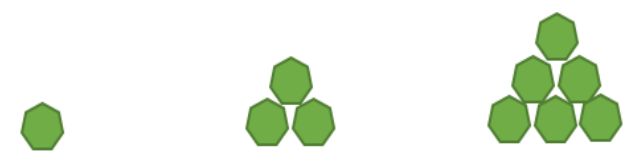

How many biscuits are needed to arrange the $5^{\text {th }}, 10^{\text {th }}$, and $n^{\text {th }}$ patterns?

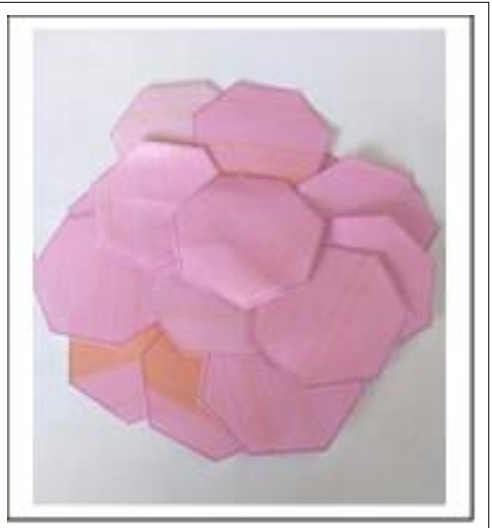

Figure 2

The second mathematical problems test instrument (left) and concrete media (right)

International Journal of Instruction, January2019 • Vol.12, No.1 


\section{Data Collection and Analysis Procedures}

The data collection on the research subjects was conducted consecutively, one at a time. The data collection was done by using task-based interviews with a think-aloud method. The subjects of this study worked on mathematical problems by writing answers on the answer sheet provided and revealing what he was thinking at that time with a loud voice. If the subjects did not reveal his thinking processes, the researchers would ask probing open-ended questions to elicit a response. All activities of the subjects at the time of solving mathematical problems were recorded with a video recorder. Think-aloud method can be effectively applied to gain the data of a qualitative research. In this research, the participants have to speak aloud any words that they are thinking when they complete task. Think-aloud research methods have a strong theoretical basis with a valid source of data about what is in participant's mind during the language based activities (Charters, 2003).

Analysis of the data used the answer sheet of subject, the transcripts from the video recording and interpretations of the subject behaviours while they solve the problems. The data was categorized into four categories, understanding the problems, devising a plan, carrying out the plan, and looking back data.

\section{FINDINGS}

This study revealed the cognitive processes of each subject as they solved the second level arithmetic sequence problems. The cognitive processes involved reading and paraphrasing the problems, visualizing the problems and representing them in the form of drawings or diagrams, determining the hypothesis to create a plan to solve the problems, estimating or predicting an answer to the problem, completing computations, and finally, checking to ensure the process of problem solving resulted in a correct answer.

\section{Subject 1: Rafi}

Rafi read the problem in a low voice while emphasizing certain words. He read the problems while he smiled, laughed to himself, mumbled and stared at the researcher. This interview transcript represents the description.

\footnotetext{
Researcher : This is a mathematical problem, can you read and understand it before doing the task?

Rafi : (He read the mathematical problem in a low voice and gave emphasis on some words. He read the problem while smiling, laughing and looking at the researcher. In the end of reading the problem, he looked at the researcher and murmured).

Researcher : Have you read (it)?

Rafi : I have.

Researcher : Do you understand the problem?

Rafi : Yes, I do.
} 
He did not read all the words in the problems. He gave much attention to numbers and the provided image of the problems. This interview transcript represents the description.

Researcher : In your opinion, which information is the most important to solve the problem?

Rafi : The most significant information in this problem is the numbers of the matchsticks.

Researcher : Do you find any other crucial information from the problem?

Rafi : No.

Researcher : Is the information from the problem enough to solve the problem?

Rafi : What do you mean?

Researcher : Do you need any other information to solve the problem?

Rafi : No.

In demonstrating, he understood the problems, he wrote a sequence starting from the first term to fifth term, calculating the difference between two terms, understanding the difference between two terms was not equal, recalculating the difference between two numbers at the next level until the same difference was obtained. He gave a conclusion that the problem was the second level arithmetic sequence. Figure 3 represents the above description.

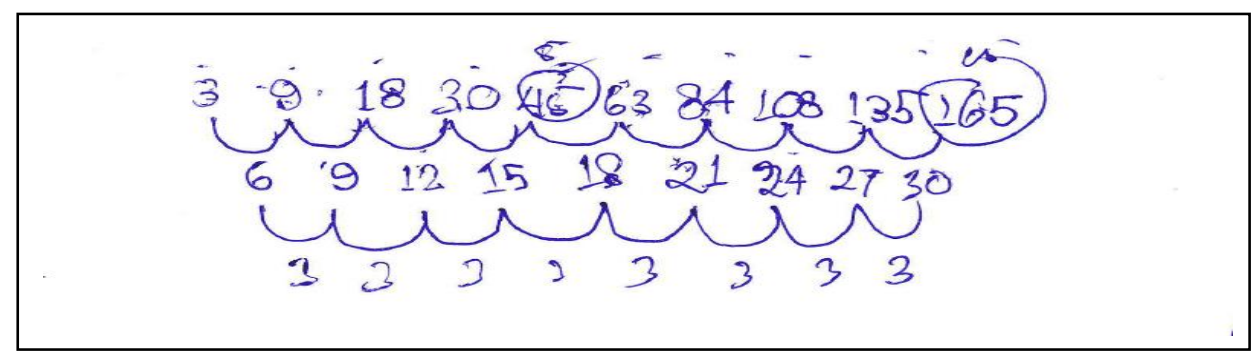

Figure 3

The pattern numbers written by Rafi

Before paraphrasing, Rafi seems to think briefly by looking up and showing his finger to try to recall the problems that has been read. In paraphrasing the problem, Rafi did not do it in a structured manner, some important information in the problems he did not mention. He put more emphasis on the image and the number in the problems. This interview transcript represents the description.

Researcher : Now can you please retell the problem with your own language?

Rafi There are sequences; three, nine, eighteen (while thinking he was looking up the ceiling and moving his pointing finger up and down) and go on, and go on with the sequence.

Researcher : What kind of sequence?

Rafi : Matches....um...matchsticks.

Researcher : And then, is there any other information from the problem?

Rafi : The information, the information I got is the first level needs three 
matchsticks, the second level needs nine matchsticks, and the third level needs eighteen matchsticks.

In visualizing the problem, Rafi did not use the media provided but he found a pattern of the sequence and a formula to solve the problems. Rather he described the problem in the form of images. Figure 4 represents the above description.

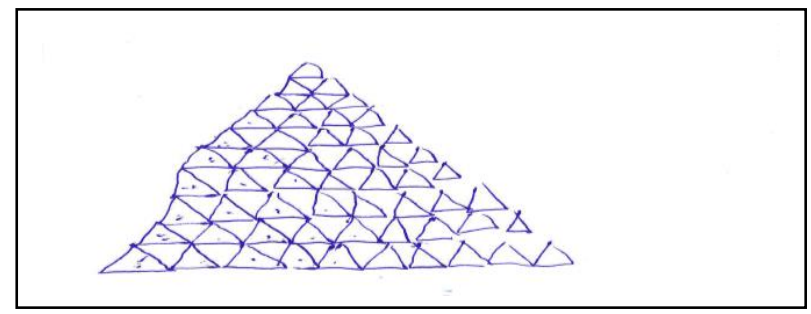

Figure 4

The visualization of the problems in the image form

Rafi developed a plan using three different methods, using pattern of the sequence (figure 5), calculating from image of the visual presentation (figure 4), and using a formula (figure 6).

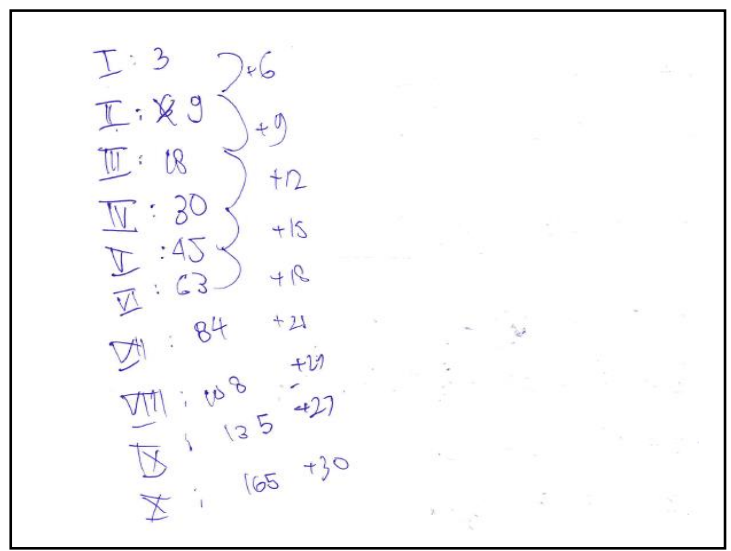

Figure 5

The pattern to solve the problem written by Rafi

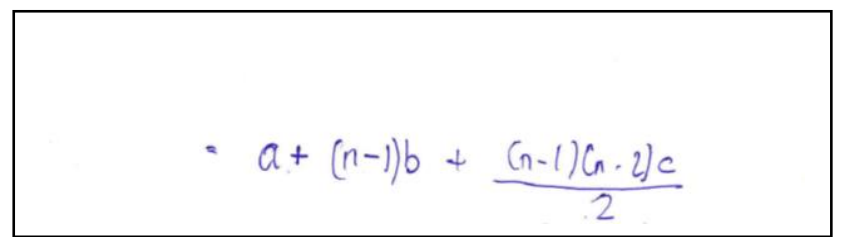

Figure 6

The formula to solve the problem written by Rafi 
Rafi could remember and verbally recall arithmetic sequence formula. Similarly, when explaining the formula, Rafi drew on previous knowledge, recalling aloud that he had worked on similar problems in the past. Rafi predicted the answer of the problem through the patterns of the sequence that has found, the images that he has drawn and the formula that he has remembered. This interview transcript represents the description.

Researcher : Have you ever worked on a problem like this?

Rafi : Yes.

Researcher : Where did you do the problem like this?

Rafi : At school and when I attended the Mathematics Olympiad

Rafi drew from his depiction of the problems and determine a solution for fifth and tenth term of sequence. He explained it was not possible to draw for the nth term. This interview transcript represents the description.

Researcher : Is it possible to answer the nth level using images?

Rafi : No, impossible.

Researcher : Why?

Rafi : Because $\mathrm{n}$ is not clear.

Researcher : What methods can be used to determine the nth level?

Rafi : Formula.

He used the formula to determine the answer for " $n$ ", recognized he made an error and corrected his calculations. During the interview process, Rafi did not look at the researchers. Figure 7 represents the description.

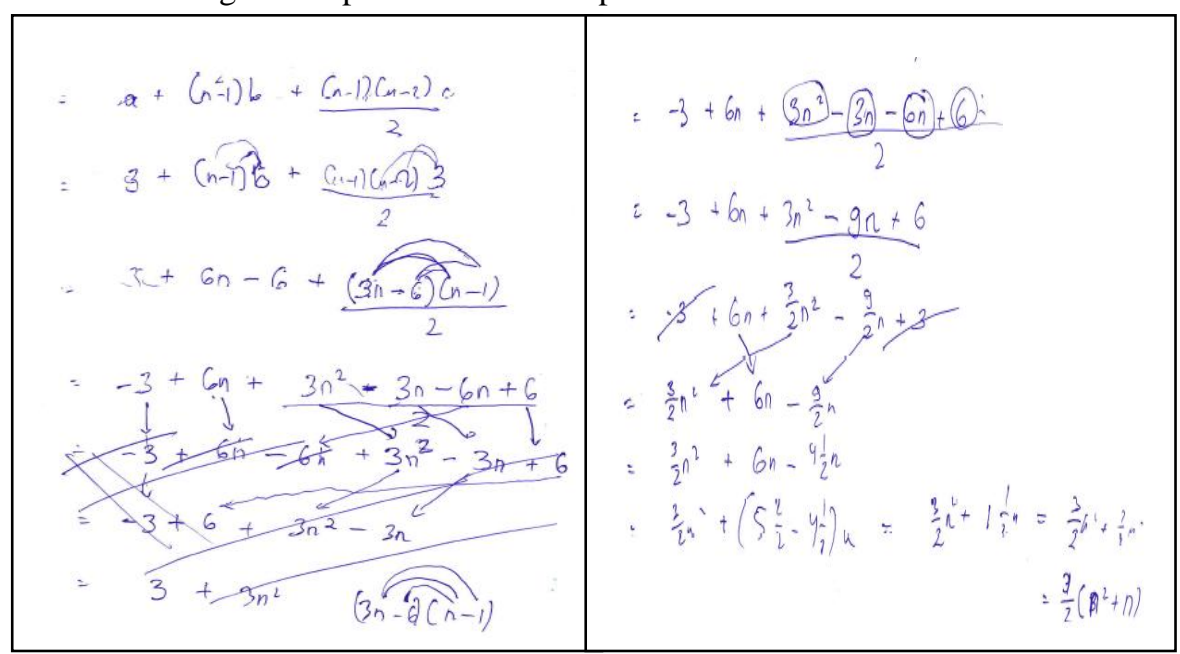

Figure 7

The formula used by Rafi to find numbers of $n^{\text {th }}$ level 
Subject 2: Aldi

Aldi read the problem in a low voice and rapid tone and gave emphases on certain words. He read all sentences in the problems. He gave more attention to numbers and pictures. Aldi was not looking at the researcher when he answered the researcher's question. He looked more ahead with a blank look. This interview transcript represents the description.

Researcher : This is a mathematical problem, I'm sure you can solve it. Please read the problem!

Aldi : (He reads the problem in a low voice while putting pressure on certain words. He reads the whole sentence in the problem. When he reads the problem several times he looks forward with a blank stare).

Aldi was unable to paraphrase the problem. He simply mentioned the problems were a sequence. Aldi mentioned the first, the second and the third term of the sequence only. This interview transcript represents the description.

Researcher : Can you please to retell the problem in your own language?

Aldi $\quad:$ (He just kept quiet and don't answer the researchers' questions)

Researcher : What is known in the problem?

Aldi : Series (with high voice).

Researcher : Oh... yes series. How many first terms of the series.

Aldi : Three (while pointing at the picture on the problem sheet, then he take the media provided to form the first level arrangement).

Researcher : What level is it?

Aldi : First (high-pitched voice).

Researcher : How about the second level?

Aldi : : (He takes the media again to compile the second level by proceeding from the first level by adding matchsticks below the first level)

Researcher : How many matchsticks are used to compile the second level?

Aldi : Nine.

Researcher : Do you still remember how many matchsticks were needed?

Aldi : (He looks Confused and recreates the first level arrangement which is separated from the 2 nd level arrangement.

Researcher : Wow, good ... how about the third level?

Aldi : (He takes the media again to compile the 3rd level and places it separately from the previous level)

Researcher : How many matchsticks are needed to make the 3rd level?

Aldi : 18

In visualizing the problem, Aldi used the media provided by researcher. He used media to represent the first, the second and the third term separately (Figure 8). 


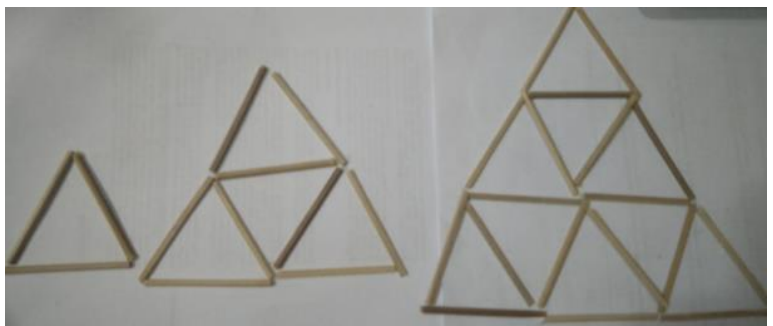

Figure 8

The visualization form of the problems described by Aldi

Aldi developed the plan of completion by writing the first, second and third term of the arithmetic sequence, determining the difference between two term and finally finding the pattern of the sequence. Aldi mentioned that he had never done a problem like this before. He predicted the answer of the problems through the pattern he had found. Aldi wrote the fourth to the tenth term of the arithmetic sequence appropriately. Each term was obtained by summing the previous term with each differentiator (Figure 9). This interview transcript represents the description.

Researcher $\quad:$ Good ... can you explain what was asked in the matter?

Aldi : How many matchsticks are needed to compile the 5th and 10th levels? (in a fast and shrill tone)

Researcher : How to answer that question?

Aldi : (He writes the first to 5th term, calculates the difference between terms, calculates the difference from the difference between the previous terms)

Researcher : How about the 10th level?

Aldi : (calculate the 6th to the 10th term, by adding the difference)

Researcher : Have you found the 10th level?

Aldi : Yes

Researcher : How many?

Aldi : 165 


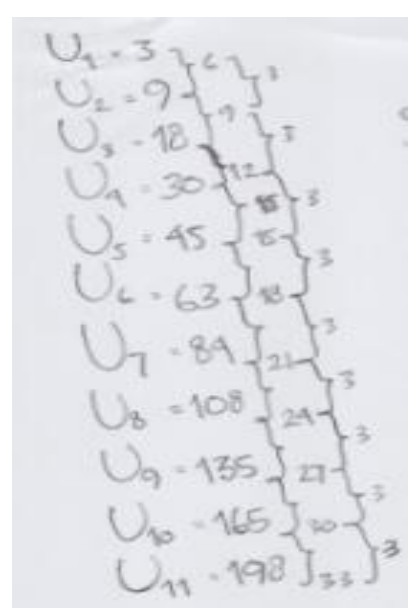

Figure 9

The pattern written by Aldi

Aldi explained that the process could not be used to determine for the nth term by any way. Aldi believed that the settlement measures were correct because the checking process had been done simultaneously during the process of working on the problems. This interview transcript represents the description.

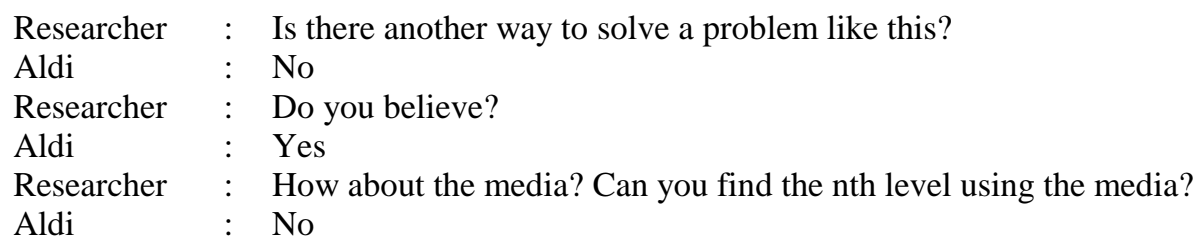

\section{DISCUSSION}

Although both subjects were able to solve mathematical problems, there were differences in the level of ability. This was most likely due to differences in the learning capacity of the subjects. Some characteristics of students with ASD were also very perceptible when they solve the problems.

In the first step, the subjects were asked to read the problem, and this was the first cognitive process observed. At the time of the reading process there were some differences between the two subjects. The first subject did not read the whole sentence in the problems, whereas the second subject did the opposite, although both gave more attention to the numbers and images in the problems. At the time of reading the problem, some characteristics of ASD were very noticeable with the first subject. He read the problems with a smile, a laugh of his own, and he mumbled to himself. However this was not seen in the second subject. Both subjects appeared to focus attention on a particular word, especially when reading numbers or at the end of a sentence. In the 
process of understanding the problems, the two subjects appeared different; the first subject ensured that the problem was a problems of second level arithmetic sequence by writing down a sequence of numbers and determining the difference of each two terms. This is in contrast to the second subject who simply mentioned that the problem was a sequence without regard to the level arithmetic sequence.

The second step of cognition process observed was the paraphrase process. The subjects were asked to paraphrase the problems into their own words or explain the important information of the problem. In this process both subjects had very different abilities. The first subject explained the problem, but the explanation was unstructured; he only mentioned a certain part of the problem and some important information from the problem was not mentioned. He tended to identify the numbers and image in the problems, while the second subject was not able to retell the problem he read. When the researcher asked him to explain the information in the problem, the second subject only mentioned that the problems related to the concept of sequence. This proves that it is true that ASD students have a disruption in communicating ideas because of their difficulty in communicating (Farrugia \& Hudson, 2006). But this does not mean he is incapable of understanding the problem.

The next process of cognitive was the process of visualizing problems to assist in problem solving. The first subject did not use concrete media in visualizing the problem, but employed drawing to find the pattern of the sequence, and in fact he gave the formula that can be used to solve the problem. However, the second subject visualized the problem through concrete media and gradually found a pattern through the use of media. In general, both subjects were able to think abstractly starting from a concrete object or from an image (Jitendra, Griffin, Deatline-Buchman, \& Sczesniak, 2007). This demonstrates that the form of visualization they build is able to make a real contribution to problem solving skills and help students to move to an abstract level of representation. This is incompatible with previous studies focusing on the cognitive difficulties ASD students have with abstract concepts and organizing information (Happe, Booth, Charlton, \& Hughes, 2006).

The next process of cognitive was to hypothesize or develop a plan for solving problems. Both subjects again appeared to show a very significant difference. The first subject showed no difficulty in this part and was even able to arrange three different plans, namely by using the pattern of the sequence, calculating the visualized image and using the formula. He quickly remembered the formula and said that he had done almost the same thing in the past. The first subject demonstrated high confidence in solving the problem after he developed a settlement plan in three different ways. This supports research from (Luculano et al., 2014), that ASD students with high intelligence are very strong in the field of mathematics. The second subject was only able to prepare a plan of completion in one way; that is by using the pattern of the sequences that had been registered. The second subject is unable to remember the formula.

The next cognition process was prediction. Both subjects were quickly able to make estimates. Both subjects estimated the solution of the problem by using the pattern of the sequence they had found. However, only the first subject was also able to estimate that 
computing the nth term can only be done by using the formula. He realized that neither drawing nor registering a number sequence can be used to determine it. These findings clearly indicate that ASD students with high levels of intelligence are able to think abstractly.

The next process of cognition was the strategy to calculate. At the time of calculating, the first subject counted very quickly by writing the term up to the tenth term. Next, he did the checking by counting through the picture. After feeling that the calculations corresponded to the manual counting of the images, the first subject laughed and mumbled in an unclear voice. The first subject used the formula to count the same solution for the problem. In the process of using the formula, he experienced some errors in algebraic operations, but he quickly realized his mistake and fixed it right away. In contrast, the second subject re-wrote the 4th and 5th term to get the solution of the problem, but was unable to find the nth term because he did not invoke the formula. This is most likely re-influenced by factors of intelligence differences between the subjects.

The last process of cognition observed was checking back over the method of solving the problems that had been done. It seems that both subjects had similarities in this process. Both subjects only had a short time to check the answer, and both were sure that the answer was correct because they checked it during the process of completing it.

\section{CONCLUSION}

Both subjects in this study were able to understand the problem but they had difficulties in communicating ideas at the paraphrase stage of the problems. At the stage of visualizing the problem they were able to think abstractly starting from a concrete object or an image. Through the concrete objects or the image they were able to find patterns that could be used to assist in solving the problems.

However, at the stage of determining the hypothesis to create a plan to solve the problems, estimating or predicting an answer to the problem, completing computations, there were significant differences in ability because it was influenced by different levels of intelligence. This shows that the mathematical ability of ASD students with high intelligence is better than low-intelligence ASD students.

Behaviouristic characteristics of students with ASD are highly visible in the process of solving mathematical problems, such as omit smiling, laughing to themselves, mumbling, and staring blankly.

\section{Acknowledgments}

We would like to acknowledge the support of Flinders University, Adelaide, South Australia and State University of Surabaya, East Java, Indonesia. We appreciate the participation of students, teachers, and parents.

\section{Declaration of conflicting interests}

The authors declared no potential conflicts of interest with respect to the research, authorship, and/or publication of this article. 


\section{Funding}

This study was supported with funding from Directorate General of Resources for Science, Technology \& Higher Education of Ministry of Research, Technology and Higher Education (KEMRISTEK DIKTI) based at Jakarta, Indonesia as a scholarship funding for Ph.D. program at Universitas Negeri Surabaya, Indonesia.

\section{REFERENCES}

Anderson, J. R. (2015). Cognitive Psychology and Its Implication. New York: W. H. Freeman and Co.

Bae, Y. S., Chiang, H.-M., \& Hickson, L. (2015). Mathematical Word Problem Solving Ability of Children with Autism Spectrum Disorder and their Typically Developing Peers. Journal of Autism Development Disorder, 2200-2208.

Barnett, J. E. H., \& Cleary, S. (2015). Review of Evidence-based Mathematics Interventions for Students with Autism Spectrum Disorders. Education and Training in Autism and Developmental Disabilities, 172-185.

Bourke, J., Klerk, N. d., Smith, T., \& Leonard, H. (2016). Population-Based Prevalence of Intellectual Disability and Autism Spectrum Disorder in Western Australia Medicine Journal, 1-8.

Braun, K. V. N., Christensen, D., Doernberg, N., Schieve, L., Rice, C., Wiggins, L., . . Marshalyn. (2015). Trends in the Prevalence of Autism Spectrum Disorder, CerebralPalsy, HearingLoss, Intellectual Disability, and Vision Impairment, Metropolitan Atlanta,1991-2010. PLoSONE10(4):e0124120. doi:10.1371/journal.pone.0124120,1-21.

Charters, E. (2003). The Use of Think-aloud Methods in Qualitative Research An Introduction to Think-aloud Methods. Brock Education, 68-82.

Chiang, H. M., \& Lin, Y. H. (2007). Mathematical ability of students with Asperger syndrome and high-functioning autism Autism, 547-556.

Demirela, M., Dermana, I., \& Karagedika, E. (2015). A study on the relationship between reflective thinking skills towards problem solving and attitudes towards mathematics. Paper presented at the 7th World Conference on Educational Sciences, Athens.

Director General of Primary and Secondary Education, M. o. E. a. C. (2017). Determination of education unit implementing curriculum 2013. Jakarta: Ministry of Education and Culture.

Elsabbagh, M., Divan, G., Koh, Y.-J., Kim, Y. S., Kauchali, S., Marcín, C., . . . Fombonne, E. (2012). Global Prevalence of Autism and Other Pervasive Developmental Disorders Autism Research, 160-179.

Evaluation, I. f. H. M. a. (2017). Autistic Spectrum Disorders in Indonesia Relative to Impact in Broader Regions Over Time. Wahington USA: University of Washington. 
Farrugia, S., \& Hudson, J. (2006). Anxiety in Adolescents With Asperger Syndrome: Negative Thoughts, Behavioral Problems, and Life Interference Focus on Autism and Other Developmental Disabilities, 25-35.

Fleury, V. P., Hedges, S., Hume, K., Browder, D. M., Thompson, J. L., Fallin, K., . . Vaughn, S. (2014). Addressing the Academic Needs of Adolescents With Autism Spectrum Disorder in Secondary Education. Remedial and Special Education, 68-79.

Fordyce, T. A., Leonhard, M. J., \& Chang, E. T. (2017). A Critical Review of Developmental Exposure to Particulate Matter, Autism Spectrum Disorder, and Attention Deficit Hyperactivity Disorder. Journal of Environmental Science and Health, $1-31$.

Frith, U. (2003). Autism: Explaining the Enigma. UK: John Wiley \& Sons.

Happe, F., Booth, R., Charlton, R., \& Hughes, C. (2006). Executive Function Deficits in Autism Spectrum Disorders and Attention-Deficit/Hyperactivity Disorder: Examining Profiles across Domains and Ages. Brain and Cognition, 25-39.

Holaday, B. (2012). History of Autism: The South Carolina Nurse.

Huberman, A. M., Miles, M. B., \& Saldana, J. M. (2013). Qualitative Data Analysis. United States: SAGE Publications Inc.

Jitendra, A. K., Griffin, C. C., Deatline-Buchman, A., \& Sczesniak, E. (2007). Mathematical Word Problem Solving in Third-Grade Classrooms. The Journal of Educational Research, 283-302

Joseph, R. M., Tager, H., \& Lord, C. (2002). Cognitive Profiles and Social Communicative Functioning in Children With Autism Spectrum Disorder. Journal Child Psychology Psychiatry, 807-821.

Long, C., Gurka, M., \& Blackman, J. (2011). Cognitive Skills of Young Children with and without Autism Spectrum Disorder Using the BSID-III. Journal of Autism Research and Treatment.

Luculano, T., Lee, M. R., supeker, K., Lynch, C. J., Khouzam, A., Philips, J., . . . Menon, V. (2014). Brain Organization Underlying Superior Mathematical Abilities in Children with Autism. Society of Biological Psychiatry, 223-230.

Marois, R. (2005). Capacity Limits of Information Processing in the Brain. Phi Kappa Phi Forum, 30-33.

Matlin, M. W. (2005). Cognition. USA: John Wiley \& Sons, Inc.

Mayer, R. E. (2011). Thinking, Problem Solving, Cognition. California: Worth Publishers.

Merriam, S. B. (2009). Qualitative Research : A Guide to Design and Implementation. Chichester, United Kingdom: John Wiley and Sons Ltd. 
Minister of National Education, t. R. o. I. (2009). Inclusive Education. Jakarta: Minister of National Education of the Republic of Indonesia.

Montague, M. (2013). The Solve It! Instructional Approach Yields Evidence-Based Results for Math Students. Reston, VA: Exceptional Innovations.

NCTM. (2000). Principles and Standards for School Mathematics. US: National Council of Teachers of Mathematics

Neef, N. A., Nelles, D. E., Iwata, B. A., \& Page, T. J. (2003). Analysis of Precurrent Skills in Solving Mathematical Story Problem. Journal of Applied Behavior Analysis, 21.

Neisser, U. (2014). Cognitive Psychology. Newyork: Psychology Press.

Parner, E. T., Thorsen, P., Dixon, G., Klerk, N. d., Leonard, H., Nassar, N., . . Glasson, E. J. (2011). A Comparison of Autism Prevalence Trends in Denmark and Western Australia. Journal of Autism Development Disorder 1601-1608.

Polya, G. (1948). How to Solve it, A New Aspect of Mathematical Method. New Jersey: Princeton University Press.

Polya, G. (1957). A New Aspect of Mathematical Method. New York: Doubleday \& Company, Inc.

Reed, S. K. (2007). Cognition, Theory and Applications. USA: Wadsworth/Thomson Learning.

Reynolds, A. G., \& Flagg, P. W. (1983). Cognitive Psychology. BOSTON: LITTLE, BROWN.

Rice, L. (2009). Prevalence of Autism Spectrum Disorder-Autism and Developmental Disabilities Network Journal of Autism and Developmental Disorders, 1-20.

Roux, C., Dion, E., Barrette, A., Dupéré, V., \& Fuchs, D. (2015). Efficacy of an Intervention to Enhance Reading Comprehension of Students With High-Functioning Autism Spectrum Disorder. Remedial and Special Education 2015, 131-142.

Solso, R. L., Maclin, O. H., \& Maclin, M. K. (2008). Cognitive Psychology. Boston: A Simon \& Schuster Company.

Spector, J. E., \& Cavanaugh, B. J. (2015). The Conditions of Beginning Reading Instruction for Students With Autism Spectrum Disorder. Remedial and Special Education, 337-346.

Sternberg, R. J., \& Sternberg, K. (2015). Cognitive Psychology. Canada: Cenveo Publisher Service.

Sun, X., \& Allison, C. (2009). A review of the prevalence of Autism Spectrum Disorder in Asia Research in Autism Spectrum Disorders, 156-166. 
Tan, P., \& Alant, E. (2016). Using Peer-Mediated Instruction to Support Communication Involving a Student with Autism during Mathematics Activities: A Case Study. Assistive Technology, 1-7.

Titeca, D., Roeyers, H., Josephy, H., \& Ceulemans, A. (2014). Preschool Predictors of Mathematics in First Grade Children With Autism Spectrum Disorder. Reseacrh in Developmental Disabilities, 2714-2727.

Whitby, P. J. S. (2012). The Effects of Solve It! on the Mathematical Word Problem Solving Ability of Adolescents With Autism Spectrum Disorders. Focus on Autism and Other Developmental Disabilities, 78-88. 